\title{
PUBLICIDADE MIDIÁTICA E MEMÓRIAS DE ELEFANTE
}

\section{Media advertising and elephant memories}

\section{PubliCIDAD en los medios y las memorias de elefantes}

\author{
Luiz LZ Cezar Silva dos SANTOS ${ }^{1}$
}

\section{Resumo}

A publiCIDADE como um conceito de publicização dos espaços públicos é o foco da discussão do presente artigo. O corpus de análise é composto por cartazes com a ilustração antiga de um elefante contendo a frase "A Revolução não será televisionada" espalhados na Avenida Paulista na cidade de São Paulo. Os cartazes servem como peças ilustrativas de mensagens críticas contra a mídia. A análise perpassa a publiCIDADE e suas relações imagéticas com as memórias do cotidiano expressas nas ruas e avenidas das grandes metrópoles, instaurando o diálogo entre Publicidade, memória e cidade.

Palavras-chave: ilustração, publicidade, cartaz, mídia, memória, cidade.

\begin{abstract}
Advertising as a concept of publicness of public spaces through the study of posters with the old illustration of an elephant containing the phrase "The Revolution will not be televised" scattered on Paulista Avenue in São Paulo. The posters serve as illustrative pieces of critical messages against the media, advertising and the imagistic relations with everyday memories expressed in the streets and avenues of the great metropolises.
\end{abstract}

Keywords: illustration, advertising, poster, media, memory, city.

\section{Resumen}

La publiCIDAD como un concepto de lo público de los espacios públicos a través del estudio de los carteles con el viejo ejemplo de un elefante que contiene la frase "La revolución no será televisada" dispersos en la Avenida Paulista en Sao Paulo. Los carteles sirven como piezas ilustrativas de los mensajes críticos contra los medios de

\footnotetext{
${ }^{1}$ Professor Doutor do curso de Comunicação - Publicidade e Propaganda - Facom/ILC/UFPA. E-mail: lzcezar@ufpa.br
} 
comunicación, la publicidad y las relaciones con los recuerdos cotidianos imaginistas expresadas en las calles y avenidas de las grandes metrópolis.

Palabras-clave: ilustración, publicidad, cartel, medios de comunicación, memoria, ciudad.

\section{UM ELEFANTE INCOMODA MUITA GENTE}

Em maio de 2015 ao andar ou se quiser, ser mais baudelairiano, ao "vagar" pelas ruas e avenidas da cidade de São Paulo me deparei com três cartazes propagandeando mensagens contemporâneas, todas relacionadas a criticas a mídia, em especial a televisão, e a publicidade. Todos os cartazes traziam o título, em caixa alta, afirmando: "A REVOLUÇÃO NÃO SERÁ TELEVISIONADA". ${ }^{2}$ O que me fez lembrar as palavras de Calvino (1990:17), "os olhos não vêem coisas mas figuras de coisas que significam outras coisas", e mais ainda: "O olhar percorre as ruas como se fossem páginas escritas: a cidade diz tudo o que você deve pensar, faz você repetir o discurso" (1990:18). Assim, para dar início a discussão precisamos rememorar a palavra "revolução", um termo que traz em seu bojo, principalmente, a ideia de mudança politica, ou seja, a mudança de um regime politico por outro:

Entretanto, há outra fonte para esse conceito, que consiste na consideração das próprias mudanças politicas, as quais foram julgadas suficientemente importantes para merecer o nome de "revolução", enquanto mudança súbita destinada a estabelecer uma nova ordem, ou a restabelecer, por meios violentos, uma ordem anterior considerada mais justa ou adequada. (Mora 1998:632).

A revolução consiste também em uma mudança ou em uma transformação radical com relação a questões sociais, econômicas, culturais, religiosas e uma infinidade de outras questões; a revolução é sempre súbita e violenta ao promover uma ruptura da ordem estabelecida e, na maioria das vezes, são de ordem politica, social e econômica.

$\mathrm{O}$ ato ou o efeito de revolver ou revolucionar é o significado da palavra de origem latina revolutione. Já do ponto de vista histórico a palavra revolução apresenta dois significados, um que diz respeito a uma mudança radical no sistema politico vigente e outro com relação a uma transformação em um sistema de produção. Historicamente o mundo já viveu diversas revoluções, dentre elas: a Revolução Inglesa (1641 a 1649); a

\footnotetext{
${ }^{2}$ Nome de uma música lançada nos EUA, em 1970, por Gil Scott-Heron. Também é o nome de um Documentário dirigido e filmado por Kim Bartley e DonnachaO'Briain, em 2002, sobre o golpe contra o governo do presidente Hugo Chávez, na Venezuela.
} 
Revolução Francesa (1789 a 1799); a Revolução Industrial (segunda metade do século XVIII); a Revolução Cubana (1959); a Revolução Russa (1905) e a de (1917); a Revolução na China (1949 a 1962). Em terras brasileiras temos a Revolução Farroupilha (1835 a 1845) e a Revolução de 1930. Não é a toa que segundo Le Goff (2003:209), “Os hábitos de periodização histórica levam, assim, a privilegiar as revoluções, as guerras, as mudanças de regime político, isto é, a história dos acontecimentos”. Desse modo, a "revolução" divulgada pelos cartazes está presente no cotidiano da cidade, mesmo que não seja televisionada.

Portanto, a que ser ressaltado a questão de ser ou não "TELEVISIONADA", a Revolução propagandeada pela mensagem-título dos cartazes. Para Attali (1998:373), as redes de Televisão oferecerão amplo acesso aos nômades virtuais, por serem "simulacros de viagens, espetáculos, distrações, maneiras de esquecer a precariedade do mundo. Nada em matéria de instrução, informação, educação. Só serão sintonizadas pelas famílias tradicionais e pelos mais pobres". Então como fazer "revolução" se as pessoas, a massa, a multidão não tem ou terá instrução, informação e educação; será talvez: “Quando as revoltas alcançarem uma tradução coletiva, quando a miséria e suas causas forem teorizadas, certas forças sociais tornar-se-ão novamente capazes de derrubar regimes incapazes". (Attali 1998:344). Até porque, "nenhum poder seria capaz de manter-se se as cidades se tornarem lugar de falências e revoltas". (Attali 1998:101).

A Cidade incumbe o trabalho intelectual: funções de organização e de direção, atividades políticas e militares, elaboração do conhecimento teórico (filosofia e ciências). A totalidade se divide; instauram-se separações, inclusive a separação entre Physis e o Logos, entre teoria e prática e, na prática, as separações entre práxis (ação sobre os grupos humanos), poiésis (criação de obras), techné (atividade armada com técnicas e orientada para os produtos). (Lefebvre 2001:36).

No universo espacial das cidades, "o cartaz é um elemento da vida cotidiana de países capitalistas, povoa a cidade de imagens e cria nosso ambiente”. (Moles 1974:64). Sem nos esquecermos de que os muros da cidade não são, em princípio, feitos para que neles sejam colados cartazes e, portanto, "A cidade é um mundo de ruas e casas, de objetos e imagens; é um campo semântico de sinais luminosos e tabuletas de lojas, de injunções e solicitações, uma paisagem artificial criada pelo homem, o elemento fundamental da cultura Ocidental”. (Moles 1974:18-19). Outro ponto que deve ser observado é a questão da retenção do olhar sobre o cartaz afixado nos muros e paredes da cidade, principalmente, em lugares de grande fluxo de passagem e de circulação de 
pessoas (transeuntes), pois, que a mesma está relacionada às questões de sentido imagem + texto e/ou texto + imagem.

A quase totalidade de imagens de cartazes no meio urbano pertence à categoria das imagens comentadas, isto é, aquelas cujo sentido se constrói tão-somente por intermédio de uma palavra ou de um texto escrito, muitas vezes sumário, mas onde o binômio imagem + seu comentário é indissociável. (Moles 1974:19-20)

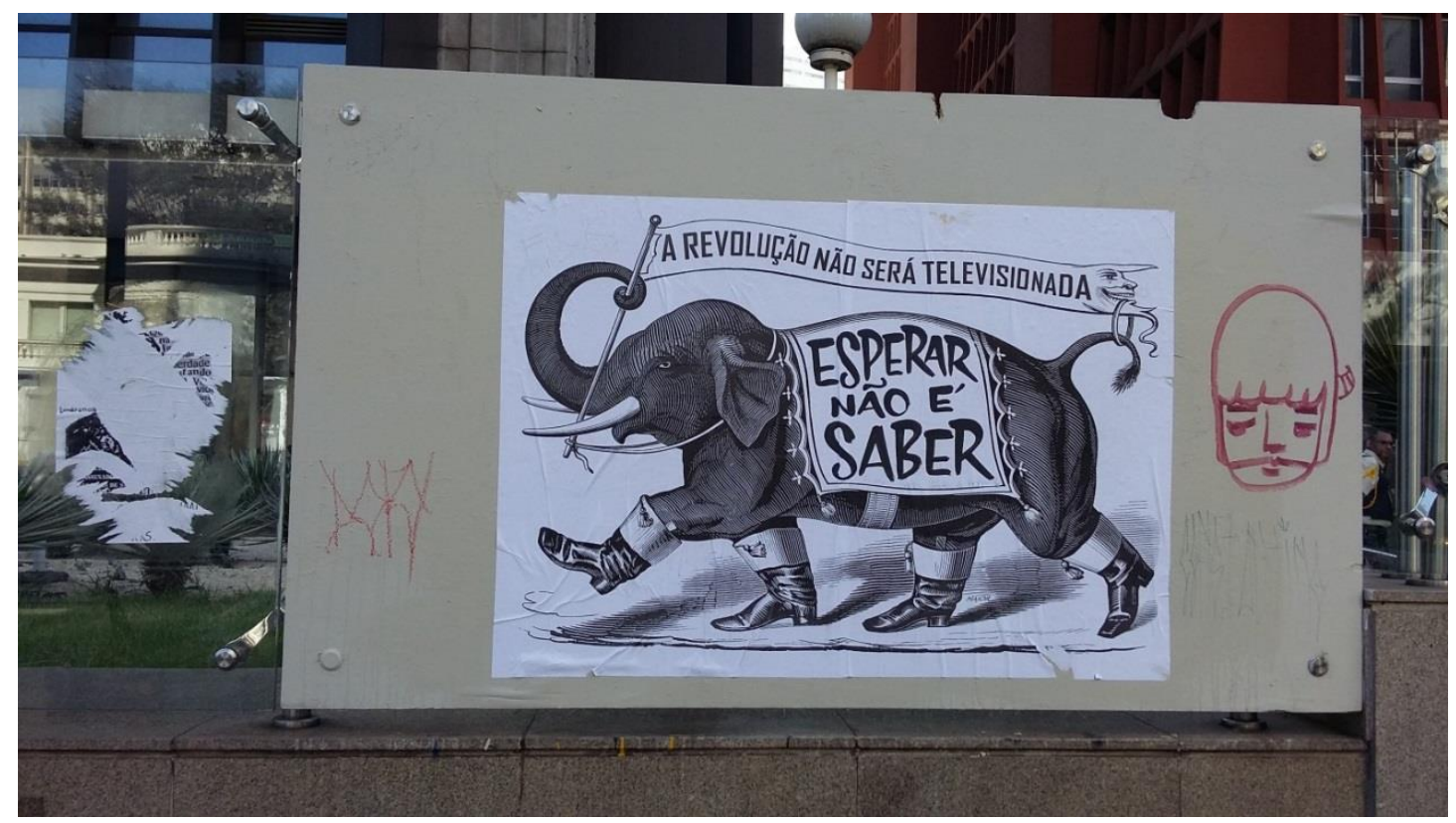

Figura 1 Cartaz - A Revolução não será televisionada. Esperar não é saber Fonte: Fotografia do Autor, maio de 2015 (Av. Paulista - São Paulo - Brasil).

A frase subtítulo utilizada na mensagem do cartaz (Figura 1): "ESPERAR NÃO É SABER" é retirada do refrão "Vem, vamos embora / Que esperar não é saber / Quem sabe faz a hora, / Não espera acontecer”, da música popularmente conhecida como “Caminhando", mas que o título original é Pra não dizer que não falei de flores (1968). A música tornou-se com o passar dos anos, durante o regime militar (1964/1978), um hino das esquerdas brasileiras na luta contra a ditadura militar, pela mudança do regime totalitário e a volta da democracia ao país. E um dos locais de manifestações contra o regime militar são as ruas, as avenidas, as praças, todos são logradouros públicos utilizados pela população, pelos cidadãos, como espaços de manifestações dos mais diversos matizes econômicas, politicas, culturais e sociais.

A Paulista arquitetônica é lugar de transito e de trafico de veículos e pedestres, espaço urbano e também avenida midiática, espaço que é mostrado na televisão e nas publicidades e que remete a outros sentidos. 
Talvez devêssemos introduzir aqui uma distinção entre a cidade, realidade presente, imediata, dado prático-sensível, arquitetônico - e por outro lado o "urbano", realidade social composta de relações a serem concebidas, construídas ou reconstruídas pelo pensamento. (Lefebvre 2001:54).

A Avenida Paulista surge da ideia de proporcionar um espaço planejado para que os ricos membros da burguesia da cidade de São Paulo pudessem desfilar toda sua pompa e circunstância. Inaugurada em 8 de dezembro de 1891 tornou-se uma larga e imponente avenida e com o passar dos anos é o lugar do coração pulsante da cidade tornando-se um dos símbolos da pauliceia desvairada.

Muitas polêmicas foram levantadas, discutindo-se a legitimidade da arquitetura. Mas a verdade é que a avenida foi vitrine fiel do seu tempo, espelhou gostos, culturas, influências, estilos, assimilações da sociedade vigente. Havia o kitsch despropositado, mas se viu também bom gosto. Com suas torres, minarete, terraços, varandas, colunatas, ferro rendilhado, vitrais, florões, telhados de ardósia, representava fantasias, mas também experimentações, adaptações e criatividade. Alguns dos mais importantes arquitetos do início do século atuaram na Paulista. Mas há legitimidade indiscutível: o marco que a Paulista significou e o impacto. ${ }^{3}$

A avenida segundo o site Paulista Viva é o lugar, "Onde tudo acontece e se determina, coração financeiro, símbolo. Passado e futuro se mesclam e perdem contornos, o tempo explode seus limites, épocas se cruzam, destinos se marcam." ${ }^{4}$ Isto posto porque para Lefebvre (2001:52), “A cidade tem uma história; ela é a obra de uma história, isto é, de pessoas e de grupos bem determinados que realizam essa obra nas condições históricas."

Em seu plano específico, a cidade pode se apoderar das significações existentes, políticas, religiosas, filosóficas. Apoderar-se delas para as dizer, para expô-las pela via - ou pela voz-dos edifícios, dos monumentos, e também das ruas e praças, pelos vazios, pela teatralização espontânea dos encontros que nela se desenrolam, sem esquecer as festas, as cerimonias (com seus lugares qualificados e apropriados). (Lefebvre 2001:68).

O cotidiano de uma cidade como São Paulo é o reflexo de "estórias" e histórias das pessoas que vivem e sobrevivem em uma grande metrópole.

Basta abrir os olhos para compreender a vida cotidiana daquele que corre de sua moradia para a estação próxima ou distante, para o metrô superlotado, para o escritório ou para a fábrica, para retornar à tarde o mesmo caminho e voltar para casa a fim de recuperar as forças para recomeçar tudo no dia seguinte. (Lefebvre 2001:118).

Ainda, segundo Lefebvre (2001:118), “O quadro dessa miséria generalizada não poderia deixar de se fazer acompanhar pelo quadro das "satisfações" que dissimulam e

\footnotetext{
${ }^{3}$ http://www.associacaopaulistaviva.org.br/site/historia.php Acessado em 11.03.2016

${ }^{4}$ Idem
} 
que se tornam os meios de iludi-la e de evadir-se dela". E, portanto, ocupar os espaços públicos da cidade com suas manifestações e reivindicações é parte da geografia urbana imposta pelo direito de "viver" e "morar" na cidade.

O direito à cidade se manifesta como forma superior dos direitos: direito à liberdade, à individualização na socialização, ao habitat e ao habitar. O direito à obra (à atividade participante) e o direito à apropriação (bem distinto do direito à propriedade) estão implicados no direito à cidade. (Lefebvre 2001:134).

A Avenida Paulista no coração da cidade de São Paulo simbolicamente representa a antiga "Estrada ou Caminho Real" que segundo Chevalier e Gheerbrant (1998:403), significa a via direta, a via reta. "Está em oposição aos caminhos tortuosos. Essa expressão frequentemente usada no mundo antigo também se aplica à ascensão da alma". A Paulista também simboliza a alma das ruas, os momentos e os acontecimentos que fazem parte da história da cidade.

\section{DOIS ELEFANTES INCOMODAM, INCOMODAM, MUITO MAIS.}

O cartaz é utilizado como peça publicitária para divulgar ou comunicar a existência de um produto, de um serviço ou de uma marca e deve ser composto, como manda a regra, com a maior simplicidade visual e textual sem, contudo, deixar de ser impactante visualmente para, desse modo, quebrar a monotonia ou a poluição visual presente nos muros da cidade; já que o cartaz apresenta sempre o problema da distancia entre ele e o raio de visão do consumidor/ transeunte. A concepção gráfica e visual de um cartaz moderno será, pois, segundo Moles (1974:44), “uma imagem em geral colorida contendo normalmente um único tema e acompanhado de um texto condutor, que raramente ultrapassa dez ou vinte palavras, portador de um único argumento. É feito para ser colado e exposto à visão do transeunte". Portanto, o cartaz deve proporcionar uma síntese visual e textual, principalmente, ante a junção e da leitura correta da mensagem semântica e da mensagem estética. Assim, o cartaz é um escândalo visual. Não é olhado, é visto. Segundo Moles (1974:195), "É a lei da óptica que determina sua forma. Sua leitura tem de ser instantânea. O homem da rua deve perceber o que ele quer dizer numa fração de segundo. Suas qualidades estéticas são secundarias, para não dizer supérfluas!”. Já com relação à complexidade e a inteligibilidade das relações apresentadas graficamente entre os itens apresentados podemos afirmar com relação aos cartazes aqui apresentados que a mesma deve ser apreciada pelos seus textos e pelas suas imagens, 
ambas formam subconjuntos, e pelos diferentes modos de apreensão tanto semântica quanto estética.

[...] O cartaz é, ao contrário, essencialmente uma imagem que pode criar uma multidão de evocações ou de conotações, confusas mas atrativas, que são cristalizadas por um texto sucinto de algumas palavras muito legíveis (palavras indutoras) que eliminam o campo das interpretações possíveis a quase totalidade destas interpretações para reter uma sobre a qual se dá o impacto da mensagem. (Moles 1974:215).

O uso das letras (palavras impressas em uma superfície como o papel) foi inventado com o intuito de conservar a memoria das coisas e, segundo Le Goff (2003:445), “com a expansão das cidades, constituem-se os arquivos urbanos, zelosamente guardados pelos corpos municipais". No caso aqui apresentado "aos corpos urbanos" as pessoas que trafegavam e/ou vagueiam pelas ruas e avenidas da cidade e que, a escrita segundo Le Goff (2003:445), nos remete "A memória urbana, para as instituições nascentes e ameaçadas, torna-se verdadeira identidade coletiva, comunitária”. Os cartazes em questão não são provenientes da administração municipal e nem do governo estadual ou federal, mas de uma comunidade proveniente da cidade.

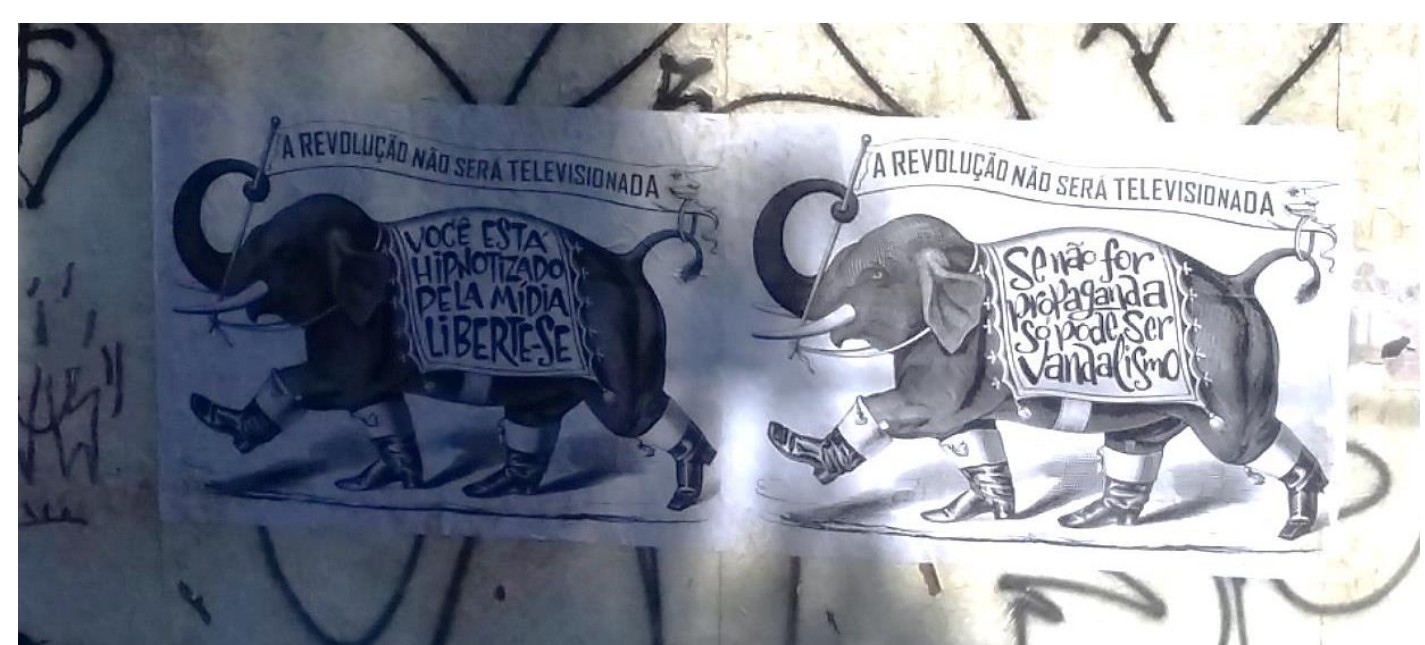

Figura 2 Cartazes: Você está hipnotizado pela mídia. Liberte-se. Se não for propaganda só pode ser vandalismo

Fonte: Fotografia do Autor, maio de 2015 (Rua Augusta - São Paulo - Brasil).

Nos cartazes em questão (Figura 2) temos uma mescla que dimensiona de maneira adequada tanto o aspecto semântico (texto escrito) quanto o aspecto estético (ilustração), ambos compondo verbal e não verbal a mensagem que se quer anunciar e as ideias que se quer propagar. Assim, a mensagem semântica ou denotativa se traduz na objetividade da frase "VOCÊ ESTÁ HIPNOTIZADO PELA MÍDIA. LIBERTE-SE" e da frase "SE NÃO FOR PROPAGANDA SÓ PODE SER VANDALISMO” CITAR FRASE expressas de maneira clara para o receptor da mensagem, o ser que caminha pela avenida. 
E, consequentemente, a mensagem estética ou conotativa é transmitida de forma subjetiva e, portanto, mensurável através da percepção pessoal da imagem, no caso, a ilustração do elefante.

Tanto que a nossa cultura ocidental difunde a imagem negativa do elefante associada à lentidão, a falta de jeito, a coisa pesada, como a expressão popular "como um elefante numa loja de cristais" ou de "louças". A expressão se refere a se sentir desconfortável em uma situação para a qual você não se sente preparado ou foi pego de surpresa, como a frase de um dos cartazes analisados: "Você está hipnotizado pela mídia. Liberte-se" (Figura 2). Desse modo, a sensação de estar e/ou ser livre nos remete ao significa de liberdade, ou seja, o direito de agir segundo o seu livre arbítrio, de acordo com a própria vontade, desde que não prejudique outra pessoa. Liberdade, também segundo a filosofia, diz respeito aos direitos inerentes a cada indivíduo, tanto em grupo quanto isoladamente, e que pode ser exercida por qualquer cidadão respeitando os limites da lei perante as autoridades constituídas no país.

Existem na língua portuguesa diversas expressões que utiliza o elefante como referencia, como por exemplo, "Memória de elefante”. Expressão utilizada para se referir às pessoas que possuem uma boa memória, que não tem problemas de esquecimento. A referida expressão vem do fato de estes animais possuírem, por questão de sobrevivência, uma facilidade de memorizar as coisas tipo locais onde conseguir água e alimentos. Outra expressão popular muito comum relacionada ao paquiderme é fazer referência a algo ou alguma coisa como um "Elefante branco".

É coisa grande e pomposa mas que não serve para nada. Sua curiosa origem vem do antigo Reino do Sião, atual Tailândia, onde o elefante branco, exemplar raríssimo entre os paquidermes, era considerado sagrado. Lá, o rei costumava dar um desses animais aos cortesãos que caíam em seu desagrado. Eles não podiam recursar o mimo nem passalo adiante, por ser presente do rei, nem fazê-lo trabalhar, muito menos matá-lo. Era um bicho sagrado.

Só restava ao infeliz agraciado alimentá-lo, acomodá-lo condignamente e trata-lo, digamos, a pão-de-ló, até porque o soberano, em visitas feitas de surpresa, costumava fiscalizar pessoalmente o tratamento dispensado ao paquiderme e punia severamente o pouco caso com ele. O animal vivia sem função, conservado apenas como dispendiosa curiosidade. Doce vingança do monarca, quem sabe uma sugestão que pode ser adaptada a governantes de nosso tempo... (Cotrim 2005:50).

A expressão também é utilizada como significado de coisa pouco prática, incomoda, trabalhosa, ou sem muito valor. O que nos remete a proposta dos cartazes de mostrar que a televisão como meio de comunicação representa um elefante branco e que, portanto, não teria nenhum valor social como meio de divulgar e explicar a "revolução" 
que está acontecendo ou está para acontecer na cidade. Assim, para Le Goff (2003:32), "Se a memória faz parte do jogo do poder, se autoriza manipulações conscientes ou inconscientes, se obedece aos interesses individuais ou coletivos, a história como todas as ciências, tem como norma a verdade”. O cartaz como peça de comunicação publicitária deve conter uma assinatura, ou seja, nome/marca do produto, serviço, empresa ou organização que assina a peça. Os cartazes em questão não possuem uma assinatura, são anônimos, transmitem mensagens, mas não dizem quem é o autor da mesma, mesmo quando fazem referencia a mídia e a propaganda. Le Goff (2003:145), nos fala da necessidade que as "sociedades têm de alimentar sua procura de identidade, de se alimentar num imaginário real; e as solicitações da media fizeram entrar a produção histórica no movimento da sociedade de consumo".

Podemos perguntar então: qual a relação da imagem do elefante com a ideia de “televisão"? Ou mesmo de "revolução"? A resposta, só se levarmos em conta o grau de abstração ou, inversamente, de iconicidade da dimensão do universo das imagens, pois, como propõe Moles (1974:97), “está ligada à propriedade que uma imagem tem de refletir o mundo real, de ser uma redução deste".

Toda história é bem contemporânea, segundo Le Goff (2003:51), “na medida em que o passado é apreendido no presente e responde, portanto, a seus interesses, o que não só é inevitável como legitimo. Pois que a história é duração, o passado é ao mesmo tempo passado e presente". Então, qual a ressonância na contemporaneidade desse fato, as mensagens propagadas pelos cartazes colados nas ruas e avenidas da cidade de São Paulo, e na mídia em geral? Pesquisando no google não encontramos nenhuma referencia textual ao fato gerador dos cartazes ou do que aconteceu, somente referencias visuais de diversos cartazes com a mesma temática gráfica (imagem do elefante) e textual (frases) apresentadas neste artigo. Mas por observação sabemos que as mesmas fazem referencia as passeatas e manifestações populares (no sentido mais lato possível) contra os governos federal, estadual e municipal. Isto serve apenas para demonstrar que não estamos inventando nada disso ou que tudo isso não passou de invencionices no photoshop, ou seja, há que tenhamos dado uma de Max Ernest e pintado o nosso próprio Elefante ${ }^{5}$ particular.

\footnotetext{
${ }^{5}$ Celebes, pintado em 1921, é uma obra significativa porque marca o período de transição de Ernst do dadaísmo para o surrealismo.
} 


\section{TRÊS ELEFANTES INCOMODAM, INCOMODAM, INCOMODAM,} MUITO MAIS

A utilização de técnicas publicitárias para criação de mensagens que propagandeiam ideias, até mesmo ideias contra a própria publicidade, é uma característica marcante tanto da época moderna quanto da era contemporânea, pois, ao ser absorvida pela sociedade a publicidade produz e reproduz não só consumo, mas também cultura.

E assim que a publicidade para os bens de consumo se torna o principal bem de consumo; ela tende a incorporar a arte, a literatura, a poesia e a suplantá-las ao utilizá-las como retóricas. Torna-se assim a própria ideologia desta sociedade, cada "objeto”, cada "bem" se desdobra numa realidade e numa imagem, fazendo parte essencial do consumo (Lefebvre 2001:69).

Em nossa pesquisa para o doutorado em História nos deparamos com o anúncio (Figura 3), da Casa Bahiana, publicado no jornal Diário de Notícias, em 22 de fevereiro de 1884, que casualmente tem como ilustração principal a mesma imagem do elefante utilizado pelos cartazes colados nos muros da Avenida Paulista.

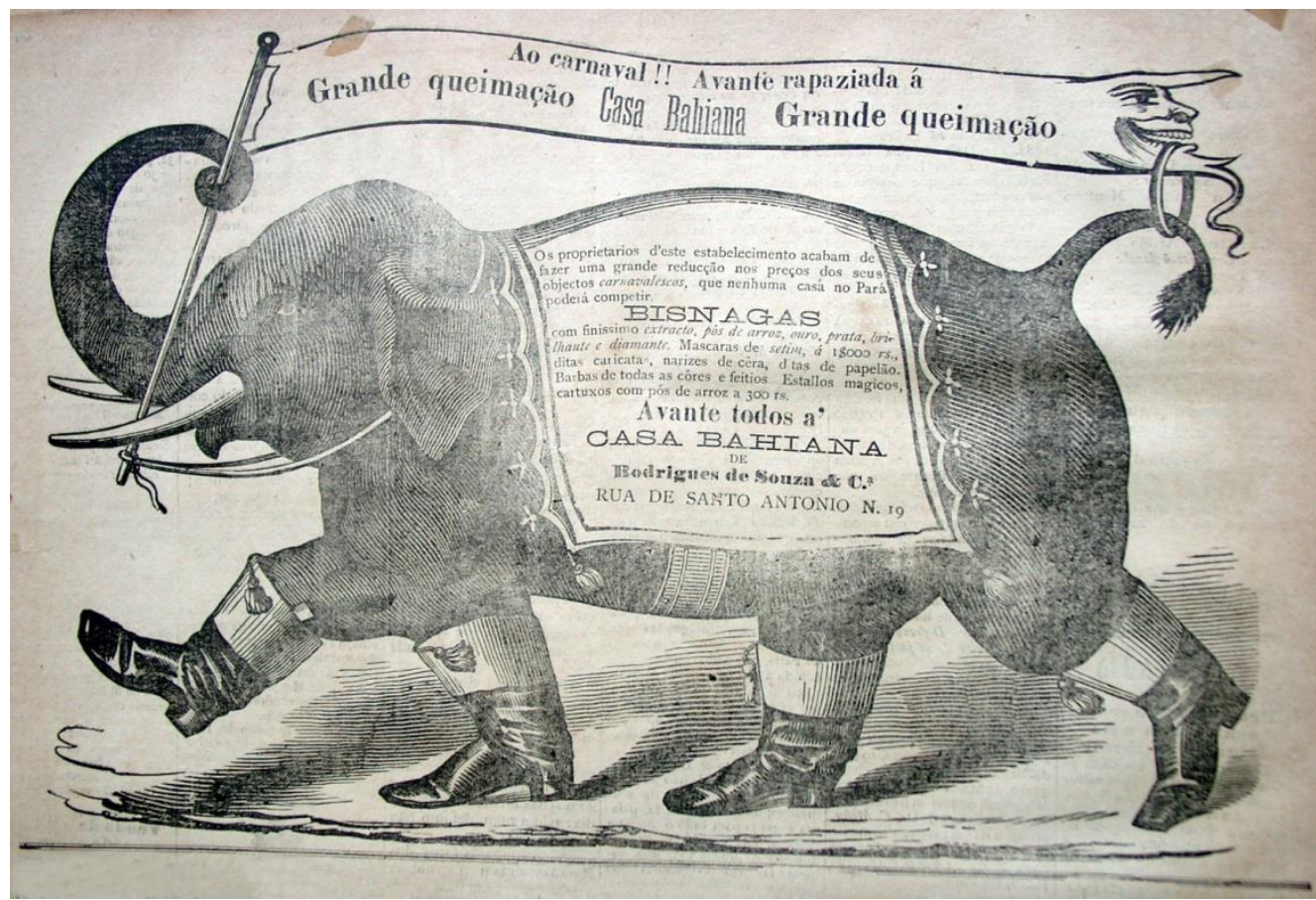

Figura 3 Anúncio - Casa Bahiana

Fonte: Jornal Diário de Notícias, publicado em 22/02/1884 (BIBLIOTECA PÚBLICA ARTHUR VIANNA, 2006-2009).

Midiaticamente, 130 anos depois, a mesma ilustração de um anúncio publicado do século XIX serve de imagem para os cartazes publicados no século XXI, isto nos remete a apropriação que a publicidade faz da mesma imagem os mais diversos usos, 
como no caso da ilustração do elefante que serve para vender mercadorias para o carnaval (século XIX) como também para anunciar a "revolução" que não será televisionada (século XXI).

A sociedade de consumo, através dos fenômenos da propaganda e da publicidade, torna os bens culturais tão próximos quanto sem valor "estético". Entretanto, ao lado disso, dão valor estético a bens culturais que lhe antecederam, conferem aura mágica e tornam mito bens culturais entre mercadorias, e obras artísticas a bens culturais que lhe precederam. (Maranhão 1988:58).

A questão da dualidade original/cópia é basicamente o fundamento principal das estéticas modernas, e estão presentes na publicidade e nas mídias de um modo geral já que é a reprodução quem dita às regras do padrão estético midiático e sendo assim, “ $\mathrm{O}$ novo jamais será original e único, jamais poderá se livrar de ser articulado com uma velha forma, ou com o que já foi novo". (Maranhão 1988:104). Na ilustração em questão temos numa alusão ao Gato de Botas através da imagem do elefante calçando botas, além de a imagem reproduzir a ideia de que ele estivesse participando de uma passeata ou de um desfile pelas ruas da cidade. $\mathrm{O}$ mesmo carrega uma faixa com dizeres publicitários, presa da trompa ao rabo do paquiderme.

Assim também com a publicidade, que elabora ou se apropria das técnicas que mais lhe convêm, entrelaça formas tradicionais de arte com as que lhe são características (em função dos seus próprios media) e prepara novas condições de existência dos consumidores que a recebem e que, por ela, têm alteradas sua visão de mundo, suas expectativas e seu comportamento pessoal, interpessoal ou grupal. (Piratininga 1994:73).

Historicamente vivemos em um mundo de imagens que fazem parte do nosso universo diário através dos meios de comunicação que nos corporificam as estéticas visuais e textuais de uma visão moderna e contemporânea de ver o mundo e que como já sabemos vivemos um universo de imagens, para Moles (1974:15): "a fotografia, o jornal, o cartaz, o cinema, a televisão, são elementos motores desta nova forma de mundo exterior, totalmente artificial, que se constituiu a cultura: o ambiente artificial construído pelo homem". Afinal, a intensidade social da atividade da publicidade e da propaganda no sistema capitalista são constantemente expressas e revigoradas pelos meios de comunicação.

A cultura é definida pelo ambiente artificial que o homem cria para si próprio, o que cada vez mais significa, muito mais que museus, quadros ou bibliotecas, o universo pessoal da concha de objetos, ou serviços de que o homem se rodeia e o universo das imagens, das fórmulas, dos slogans e dos mitos, que ele encontra na sua vida social, girando o botão da televisão, ou vagando pelas ruas. (Moles 1974:14). 
Sem esquecer que a exposição diária das mesmas mensagens reforça a ideia, mas, ao mesmo tempo, causam um desgaste visual e comunicacional junto aos transeuntes, os receptores e consumidores das mensagens e que dependendo do grau de exposição diária acabam por causar uma banalização dos objetivos e um desgaste do seu valor estético. $\mathrm{O}$ que implica numa vida útil, bastante curta, do cartaz no cotidiano da cidade.

\section{REFERÊNCIAS BIBLIOGRÁFICAS}

ATTALI, J. Dicionário do século XXI. Rio de Janeiro: Record, 2001.

CALVINO. I. As cidades invisíveis. São Paulo: Companhia das Letras, 1990.

CHEVALIER, J; GHEERBRANT, A. Dicionário de Símbolos. $12^{\circ}$ ed. Rio de Janeiro: José Olympio, 1998.

COTRIM, M. O pulo do gato: o berço de palavras e expressões populares. São Paulo: Geração Editorial, 2005.

LEFEBVRE, H. O direito à cidade. São Paulo: Centauro, 2001.

LE GOFF, J. História e memória. 5º ed. Campinas, SP: Editora da Unicamp, 2003.

MARANHÃO, J. A arte da publicidade: estética, crítica e kitsch. Campinas, SP: Papirus, 1988.

MOLES, A. O cartaz. São Paulo: Perspectiva, 1974.

MORA, J. F. Dicionário de Filosofia. $3^{\circ}$ ed. São Paulo: Martins Fontes, 1998.

PIRATININGA, L. C. Publicidade: Arte ou artifício? São Paulo: T. A. Queiroz, 1994.

SANTOS, L. C. S. publiCIDADE belle époque: A mídia impressa nos periódicos da cidade de Belém entre 1870-1912. Tese de Doutorado apresentada no programa de pós-graduação em História da Pontifícia Universidade Católica de São Paulo/PUC: 2011.

Artigo aprovado: 17/06/2016 